\title{
A EXPERIÊNCIA QUE SE VIVE DURANTE O PROCESSO DE CONSTRUÇÃO DE UM TRABALHO
}

\author{
Eliana Monteiro Moreira* \\ Maria Yara Campos Mato**
}

Nada mais oportuno do que uma homenagem a Sylvia Ostrowetsky, pessoa com quem convivemos durante quase cinco anos, durante o período de gestação e conclusão de nosso doutoramento. A experiência que se vive durante esse processo é ímpar, singular, e por ser exatamente assim é que ela nos marca e faz com que a guardemos como algo muito especial na nossa formação acadêmica. O que dá o "tom" a esses momentos é o fato deles abrigarem o confronto e o desvelamento de "realidades" contraditórias: sim, porque aqui não está em jogo apenas o revelar de nossos limites, inseguranças, imprecisões, que passam, a partir de então, a ficar sob a "regência" do orientador. Anunciam também o que nos leva a partilhar novos contornos do saber, abrindo trilhas em busca da superação dos obstáculos revelados no início da trajetória construtiva. É dentro desse embate difícil, conflitivo muitas vezes, e solitário, que vai nascendo e tomando corpo e rosto uma outra relação, a de respeito e de afeto por essa figura que, ao sinalizar nossas fragilidades, nos faz mover e, deste movimento, vem a gestação do trabalho que chega a seu término.

Isso nós gostaríamos de um dia ter lhe dito, Sylvia, pessoalmente. Como não foi possível, deixamos a você o espaço em que prefacia o que hoje se transformou em livro, este Servo de

Doutora em Sociologia pela Université de Picardie (França), pós-doutora pela Pontifícia Universidade Católica de São Paulo (PUC-SP), professora do Departamento de Ciências Sociais da Universidade Federal da Paraíba (UFPb).

** Doutora em Sociologia pela Université de Picardie (França), professora do Departamento de Ciências Sociais da Universidade Federal da Paraíba (UFPb).

Artigo recebido em 06 set. 2004; aprovado em 07 out. 2004. 
Ninguém, e suas análises e reflexões feitas em Colóquios e Congressos na França sobre Ni noir, ni blanc: métis mais beau, une étude sur les jugements esthétiques du visage dans le Nordest du Brésil, vindos do trabalho das nossas teses que você cuidou com esmero competente. Só temos a reforçar todos os nossos agradecimentos.

\section{Prefácio* a Servo de Ninguém}

"Não, eu não quero mais ser servo de ninguém..."

O título do livro de Eliana Monteiro Moreira inspirou-se nesta frase de um pequeno produtor do nordeste brasileiro. São as especificidades das pequenas unidades produtivas que compõem os espaços urbanos a meio caminho entre o comércio e a indústria que Eliana quer aqui analisar.

O termo "servo" diz muito: não se trata, de modo algum, para esses pequenos produtores, da tomada de consciência de um homem livre vendendo sua força de trabalho, à maneira de Ricardo ou de Marx. O uso do termo revela uma particular insistência sobre a dependência que toda relação de trabalho implica, para o escravo sem corpo próprio ou o "vilão" atado à gleba das sociedades feudais, como também o caso daquela, moderna, do trabalhador assalariado. Uma racionalidade introduz-se entre essas formas mais ou menos artesanais por meio da gestão mais ou menos organizada da produção e da comercialização.

Portanto, longe de considerar o assalariamento de empresa como a única via de acesso à modernidade, a pesquisa de Eliana Monteiro Moreira demonstra que a pequena empresa sempre coexistiu (e coexiste ainda hoje, mesmo nos países ditos avançados) junto à grande produção; a pequena unidade de produção familiar não significa, por conseguinte, a sobrevivência de um universo de trabalho pré-capitalista, mas, ao contrário, acompanha ao longo do tempo a grande produção.

\footnotetext{
*Tradução de Ana Monteiro.
} 
O individualismo (e seus correlatos: a autonomia e o domínio de seus próprios compromissos) é apanágio dessa espécie de intermediários entre a convivialidade artesanal e a distância social a que constrange o trabalho em série. Para dizê-lo de outro modo, tais empresas parecem autorizar uma forma de relação social cuja dependência não impede nem a familiaridade, nem a liberdade de empreendimento.

Sem pretender que as divisões hierárquicas possam ser resolvidas de modo unívoco por meio da apropriação coletiva dos meios de produção, como propõe o esquema marxista de análise, os pequenos produtores aqui presentes esboçam um espaço e um tempo do "aqui e agora", onde produção coletiva e reprodução privada da força de trabalho combinam-se de maneira pragmática.

Nossos atores, e aqueles que aderem à sua "ideologia", não são revolucionários. Deslizam de tal modo pelos interstícios do sistema que acreditam poder dele acumular todas as vantagens. "Espaço outro" da produção, circulação outra das mercadorias e dos homens, "tempo outro" da divisão do tempo doméstico, a pequena unidade de produção constitui uma "utopia realizada", uma "ucronia" em ato. Em suma, um "lugar" potencial, entendendo o termo como o encontro do espaço e do tempo, um lugar, então, onde pode "acontecer um lugar". ${ }^{1}$

Eliana pôde percebê-lo e ouvi-lo, deslocando-se várias vezes ao lugar de trabalho e durante o tempo do trabalho, porque ela viu e ouviu agirem esses homens e mulheres numa unidade de dimensões relativamente restritas, em que a separação entre espaços de produção e vida doméstica não está nitidamente estabelecida, onde o quintal e o galpão são tão utilizados quanto um quarto ou uma cozinha.

Por ocasião de sua primeira pesquisa, quando esse tipo de trabalho era ainda clandestino, notou como algumas telhas eram afastadas na calada da noite, ou na madrugada, com a intenção de deixar escapar, com cautela, uma fumaça que deveria evanescer-se para não chamar a atenção de ninguém. Aqui, tudo parece confundirse: espaço doméstico, espaço de trabalho, tempo da vida privada, 
tempo da produção. Mas, essa parcelização extrema das tarefas, reiterando a indivisão do lugar, longe de ser vivida como alienação, carrega, ao contrário, uma inversão dos valores negativos. Como diz Dona Mariana: "Todos os dias eu me levanto às cinco horas. Quando o dia clareia, vou para a cozinha e ponho água para ferver, preparo o café das crianças e de meu marido e vou lavar roupa. Enquanto a roupa está de molho, saio para fazer a entrega dos bolos. Na volta, começo a preparar o almoço. Não paro nunca. Quando tudo está bem adiantado, volto para a roupa, depois eu interrompo um pouco para acabar de preparar o almoço. Coloco no liquidificador o suco de fruta para preparar os 'din-din' e, quando estão prontos, ponho para vender no nosso fiteiro. Depois, termino de enxaguar a roupa, arrumo a casa, passo a roupa e, ao mesmo tempo, ajudo Marcos [seu marido] e Davi [um sobrinho que trabalha na unidade de produção] a preparar os bolos". Assim, como comenta Eliana, "a pulverização das tarefas não a incomoda... A imagem que faz de si mesma é a de uma mulher orgulhosa, que tem sempre muito que fazer, que está sempre ocupada, alguém que tem uma vida consagrada ao trabalho". No mesmo tom, afirma uma outra: "Para mim, o trabalho é uma riqueza, graças a ele eu posso me dedicar a meus filhos". Se a livre empresa obriga, com freqüência, o(a) proprietário(a) e seu cônjuge a trabalharem sem trégua nem descanso, de manhã à noite, essa ocupação permanente transforma-se em aposta positiva na independência. A justaposição dos espaços e o parcelamento do tempo oferecem uma solução positiva àquilo que habitualmente aparece como o cúmulo da condição feminina, o que se denomina uma "dupla jornada" de trabalho.

Como se vê, nada aqui se aproxima do que em geral é sublinhado como contradição de um sistema: o assalariamento de um lado, a dupla jornada de outro. Aqui, quer como espaço de trabalho, quer como tempo da produção ou da reprodução da força de trabalho, a pequena unidade produtiva, que não tem a pretensão de ultrapassar as contradições inerentes ao capitalismo, é um lugar que nada perde de sua capacidade operatória. É o lugar onde as diferenças se justapõem, onde as apreciações podem ser permutadas porque parecem autorizar todos os contrários. Graças ao sentimento de 
reapropriação voluntária de si, eis o lugar onde os desprazeres se transformam em prazeres, os impossíveis em possíveis, a alienação do trabalho em uma liberação.

Neste sentido, a pequena unidade produtiva representa (em João Pessoa e em todo o Brasil, mas também nos países desenvolvidos ou em vias de desenvolvimento) um espaço que parece conjugar inúmeras vantagens. Seguindo Louis Marin, diríamos que a pequena empresa esboça um lugar pleno de todas as contradições engendradas pelo sistema: "a utopia não é da ordem do conceito, nem pertence tampouco àquela da imagem: ela é figura, um esquema de imaginação, uma ficção 'produzida-produtora' de formas polissêmicas, das quais só podemos nos aproximar por meio do imaginário". ${ }^{2} \mathrm{O}$ mesmo pode ser dito daquilo que nomeamos mais acima "ucronia", ainda mais especificamente nas unidades de "confecção", onde a divisão dos tempos é extrema em relação às de "alimentação" - as duas atividades privilegiadas nesta pesquisa.

As mulheres, sobremodo as da confecção, afirmam com vigor que o trabalho é a ocasião da realização de si, não porque escapam da dupla alienação, do trabalho e da relação conjugal, mas porque podem combinar a iniciativa pessoal com aquilo que define a especificidade feminina de "especialistas da vida privada".

Na realidade, nos próprios gestos do ofício, o sexo perde sua importância. Assim, as mulheres da confecção atingem uma racionalidade que nada fica a dever (muito ao contrário) àquela dos homens do setor de alimentação. Estes, contudo, para reservarem a si mesmos as responsabilidades mais valorizadas, sabem servir-se do pretexto da técnica para reduzir as mulheres e outros subalternos a tarefas repetitivas. Demonstra-se, então, que não se trata, neste caso, de essência sexuada, mas de posições de poder na unidade de produção. As características próprias ao masculino e ao feminino são inoperantes para explicar o acesso de todos à racionalidade weberiana; melhor seria referir a uma ética do mérito, que a pequena unidade de produção metaforiza de maneira emblemática. 
Percebe-se, igualmente, como a pequena unidade produtiva interroga todos os procedimentos históricos da organização social: vida privada/vida pública, feminino/masculino, produção/reprodução. A subversão é a regra, mas isso não quer dizer que as oposições sejam postas em xeque. A respeito do espaço utópico, Louis Marin refere-se ao 'grau zero' da síntese dialética dos contrários, o que não significa ineficácia. Vida privada e vida pública não se opõem mais, mas andam lado a lado; a divisão das tarefas não desaparece porque as mulheres da confecção são capazes de se comportarem como se fossem "patrões", ao mesmo tempo em que preenchem satisfatoriamente seus papéis de mães e esposas a seu modo submissas. Os homens passam a dominar o setor de alimentação à medida que as máquinas são introduzidas e, com elas, a racionalidade que impõem, reservando a cada qual o seu lugar; na confecção, porém, a introdução da mesma divisão social não questiona essa divisão sexual. Enquanto a presença dos proprietários homens perpetua a divisão social do poder e das tarefas, sua ausência como responsáveis pela produção na confecção reconduz as mesmas divisões, como se a proximidade do espaço de trabalho e do espaço doméstico, a divisão dos tempos, a instauração desses lugares onde tudo parece possível, autorizassem, numa ironia jocosa, todas as subversões que conservam, sem nada destruir, as oposições anteriores.

Somos tentados a afirmar que, por acumulação, justaposição das contradições, a pequena unidade produtiva encena uma visão mais proudhoniana que marxista; segundo a expressão do próprio Proudhon, o lado mau das coisas dissolve-se numa positividade que só diz respeito à vontade inquebrantável de seus atores: "os socialistas moderados combatem o direito de sucessão porque não sabem fazer dele uma maneira de conservar a igualdade; os seguidores de Fourier e de Saint-Simon atacam a família porque seus sistemas são incompatíveis com a indústria privada, a vida íntima e o livre comércio; os comunistas atacam a propriedade porque ignoram como a propriedade deixará de ser abusiva para a mutualidade dos serviços. Ignorância confessa! É o argumento de todas essas seitas com pretensões reformadoras, argumento que traz em si mesmo sua própria 
refutação, e que basta para nos afastar de todas essas preleções humanitárias". ${ }^{3}$

Se Marx apressa-se em responder a essa obra já no ano seguinte ao de sua publicação, em 1846, é porque ele bem aquilata os riscos para o pensamento revolucionário. Em Miséria da Filosofia, Marx demonstra com brilhantismo e incansável ironia as aporias do autor: "Vê-se, o 'método histórico e descritivo' do senhor Proudhon serve a qualquer coisa, a tudo responde, a tudo explica". Imaginando que existem maneiras de tudo conservar, à condição de fazer desaparecer o lado mau das coisas, delas só guardando o que têm de bom, ele crê seguir uma dialética da qual nada entendeu: "uma classe oprimida é a condição vital de toda sociedade fundada sobre o antagonismo de classes. A liberação da classe oprimida implica então, necessariamente, a criação de uma sociedade nova", afirma Marx. ${ }^{5}$ Isso não proíbe pensar que os nefastos raciocínios de Proudhon, que ignoram o conceito de "Aufhebung" (superação) de Hegel, sua maneira de fazer prevalecer a lógica sobre a realidade - como nossos pequenos proprietários, sonhando com uma liberação por meio do trabalho sem trégua e a corrida sem fim ao longo da cadeia de um perpétuo presente -, possuem uma capacidade de impregnação que a dramaturgia marxiana não soube fazer ancorar nos fatos. Em muitas dessas entrevistas, o tempo aparece como um tempo suspenso, Kairos contra Kronos, à maneira, guardadas as devidas proporções, de G. Agambem, ao tratar do tempo messiânico. ${ }^{6}$ A justaposição de paradoxos parece frustrar todos os movimentos sociais, com um investimento quase invertido dos valores, pois o trabalho torna-se prazer e o lazer angústia de não-existência. $\mathrm{O}$ espaço de trabalho é aqui apresentado como um espaço de vida que afasta a solidão e dá sentido à existência; o tempo de trabalho é percebido como "descontraído", permitindo pausas e conversação. O ato produtivo é carregado de uma forte expressão de criatividade e de savoir-faire. Como escreve Eliana: "essas unidades, trabalhando em geral em ritmo intensivo, denotam uma ética monacal: começam o dia pela manhã bem cedo, terminam muito tarde na noite e avançam pelos finais de semana; a contrapartida é uma situação financeira mais folgada." 
Entretanto, duas variáveis devem matizar essas análises positivas. A primeira, diz respeito àqueles que conheceram uma situação salarial mais favorável, responsáveis por tarefas mais valorizadas; estes lastimam a perda do assalariamento. Depois, com relação aos parentes e trabalhadores que se mantêm dependentes do proprietário, queixando-se dos maus pagamentos, do parcelamento e da extensão do tempo de trabalho. Neste caso, a saída consiste quase sempre em querer criar sua própria empresa, coisa a que o proprietário consente. A "coreografia continua perfeita e, apesar, e graças, à camaradagem do cotidiano, os conflitos parecem diluir-se, assim como as conseqüências das irregularidades cometidas contra os trabalhadores."

Retomando uma parte de minha própria pesquisa a respeito das representações, ${ }^{7}$ Eliana Monteiro Moreira descreve os locais de produção a partir de três tipos:

- a representação "teatral" de encenação do sujeito comparável ao espaço perspectivo do Renascimento inaugurado por Masaccio, Alberti... Ei-la presente no Sr. Marcos, que é também "obreiro" da Igreja Universal do Reino de Deus;

- a "representação-semiosis" que, no essencial, gera os lugares segundo uma divisão sexual das tarefas, em que as mulheres, sobretudo no setor da alimentação, são mais freqüentemente destinadas aos trabalhos repetitivos e às atividades estritamente domésticas e em que os homens, sobretudo o proprietário, têm direito a um espaço aberto e de circulação;

- a "representação transparente", em que a função exata de cada etapa da produção, consecutiva à introdução de máquinas, por exemplo, determina de forma "óbvia" as etapas da produção.

A análise sucessiva do lugar da produção da ótica do casal ou apenas do (ou da) proprietário(a) através desses três dispositivos 
parece-nos um momento privilegiado na análise de Eliana para apreender a superposição das lógicas espaciais e temporais em funcionamento nesses locais de trabalho. Para retomar a feliz expressão de M. H. Poggi, um "espaço folheado"8, que parece confuso a olhares pouco atentos, mas que, ultrapassado o aparente imbróglio, faz bastante sentido.

Do ponto de vista metodológico, essa atenção à dimensão espaço-temporal permite compreender as implicações simbólicas na ação concreta da produção. O que assim se localiza é dominado pela ideologia da igualdade de oportunidades, pelo acesso à responsabilidade no trabalho e pelo sentimento de liberação da pessoa frente à dependência do patrão ou do marido.

Como tão bem afirma Eliana, tratava-se de descrever essa "coreografia" dos atores, este espaço-tempo da produção segundo um esquema sociossemiótico preciso. Atentar para a coreografia do espaço e do tempo da produção é, de certa maneira, escapar a essa cisão comum no vocabulário das Ciências Sociais entre representação e prática, como se uma pudesse funcionar sem a outra e reciprocamente.

O ponto de vista sociossemiótico procura demonstrar a maneira pela qual a localização dos lugares e dos tempos organiza-se em "formantes" cruciais da vida cultural e social - para retomar a terminologia de Hjelmslev -, não apenas de modo estático, mas também conforme uma dinâmica da ação. Daí o interesse do termo "coreografia" que, através da estruturação das coisas no espaço, dos movimentos dos corpos e dos gestos, indo de um ponto a outro e de um tempo a outro, conferem sua força efetiva à pessoa, permitindolhe construir verdadeiramente um "lugar", isto é, um espaço onde o tempo tem a capacidade de "fazer acontecer o lugar". 9 "

Assim, é através de suas tarefas cotidianas, suas exigências, suas formas materiais, que o "societário" orienta sua vida. Por isso, seguir as evoluções e transformações das formas espaço-temporais da produção permite apreender a maneira pela qual os atores transformam-se a si mesmos e adquirem os gestos de uma lógica do 
sentido que nem sempre se assemelha à razão aparente e desencantada do mundo capitalista. Por entre essa apreensão da gestão simbólica ou mais "racional", a questão agora é saber como se articula uma sociologia dos atores a uma pragmática dos gestos produtivos e constitutivos da pessoa, isto é, no sentido amplo do termo, um simbolismo da autonomia. Segundo esse processo de autonomização, as mulheres estão em particular vantagem, aparentemente, uma vez que se trata de domínios onde suas competências de gênero importam grandemente. No entanto, por este viés, fica comprovado que a autonomia pode vir a se constituir, paradoxalmente, do interior mesmo de uma dependência que praticamente nada indaga e nada questiona.

Eliana Monteiro Moreira mostra que a introdução do modo de produção capitalista não conduz à homogeneização das formas de produção e à homogeneização do trabalho; indica com clareza que, no Brasil como alhures, o que está em pauta é uma porosidade que somente o pensamento totalizante pôde descrever de maneira unívoca. Aqui, como alhures, os arranjos e rearranjos são regra e Durkheim não se engana quando demonstra que a racionalização não caminha em sentido inverso ao da individuação. Mas, ao passo que o individualismo da produção em série isola e dessocializa em proveito de uma competitividade darwiniana, nossos pequenos produtores querem acreditar, ao mesmo tempo, na livre empresa e na manutenção da cooperação; em uma palavra, na sociedade.

Deve-se desconfiar seriamente daqueles que afirmam, de maneira por demais simplificada, que na Europa passou-se progressivamente do artesanato à produção capitalista. Muitos historiadores, e o próprio Marx na obra citada anteriormente, ${ }^{10}$ já demonstraram que a máquina foi introduzida nas terras dos camponeses, durante o inverno. Não nos esqueçamos que as corporações foram consideradas um obstáculo à liberdade do trabalho (Lei Chapelier de 1791, na França), isto é, além da interdição do direito de associação, também à liberdade de exploração capitalista do trabalho. O fato demonstra ainda que foi contra os artesãos que surgiu o capital industrial. No Brasil, acresce-se ao processo o passivo colonial e pode-se dizer que a produção industrial, se foi ainda mais brutal nesses países, não impediu a existência das formas paradoxais 
mais vivas da expansão das formas contemporâneas de autonomização.

Esta pesquisa nos ensina duas coisas:

1) É no investimento do espaço e do tempo cotidianos que se inscreve o significado de uma vida;

2) Os lugares são carregados de uma capacidade formativa de si mesmos.

Não nos tornamos Sujeitos por obra e graça de uma pura tomada de consciência, mas através da prática concreta. É pois na criação, mesmo a mais modesta, que, como ator social e como pessoa, o indivíduo realiza-se. Realiza-se, isto é, torna-se real a si mesmo. Tal qual na cena descrita por Freud em que a criança apreende, subitamente, graças à sua imagem no espelho, sua própria unidade corporal, o lugar torna-se não mais um duplo, mas a expressão da construção do Sujeito. Como se o espaço indiviso e o tempo escandido do trabalho social estivessem encarregados de suturar o trabalhador separado de si mesmo. A heterogeneidade de um dispositivo centrado sobre o espaço próximo e a finitude do tempo não remetem à dispersão, mas a uma familiaridade que permite reunir os contrários em um encontro produtivo e satisfeito.

Podemos, então, sintetizar a análise segundo um esquema inspirado pelo "quadrado semiótico" proposto por A. J. Greimas: ${ }^{11}$

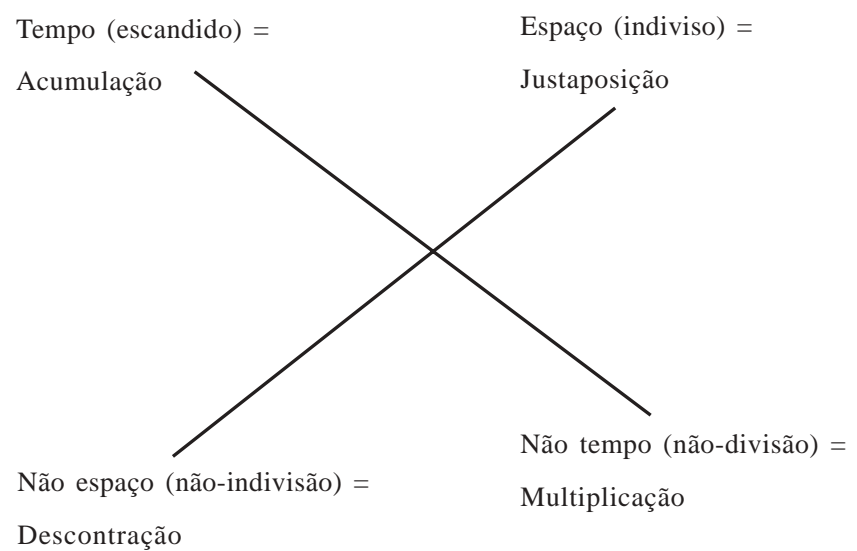


Nesses lugares da utopia e da ucronia que denominamos "realistas" porque situam-se, como o espaço-tempo messiânico, de dentro do aqui e agora, o espaço e o tempo parecem opor-se como "matérias expressivas formadas" (espaço e tempo) segundo os seus princípios de partição. Ao tempo escandido opõe-se um espaço indiviso. Manifestam-se, no nível dos usos, ora pela acumulação das tarefas, ora pela justaposição ou mesmo a superposição imaginária dos espaços. A esses "contrários" opõem-se "subcontrários" que são deles os negativos. Ao que nomeamos um "não-espaço" porque supõe que o lugar não é mais que um tempo quase elástico, descontraído, opõe-se um "não-tempo" que remete a um "compossível”, uma espécie de espaço em sanfona.

Como se pode perceber, então, a pequena unidade produtiva encontra sua inteira positividade na metamorfose imaginária do setor informal. ${ }^{12}$

Paris, 23 de agosto de 2003

\section{Notas:}

1 S. Ostrowetsky. L’imaginaire bâtisseur. Paris: Méridiens-Klincksieck, 1983.

2 Utopiques: jeux d'espaces. Paris: Editions de Minuit, 1973. p. 44.

3 Philosophie de la misère, misère de la Philosophie. 10/18, 1964, p. 227.

4 Idem, p. 321.

5 Idem, p. 491.

6 Le temps qui reste. Paris: Payot, 2000. (Bibliothèque Rivages).

7 La représentation et ses doubles. Communication-Information, Université Laval, Canadá, v. 6, n. 2-3, inverno de 1984.

8 Le quartier du Marais, le mélange et le feuilleté. MAROUF, N. (Ed.). Pour une sociologie de la forme: mélanges Sylvia Ostrovestsky. Paris: CEFRESS, L'Harmattan, 1999.

9 L'imaginaire bâtisseur, op. cit. 
10 Não foi no interior das antigas corporações que a manufatura nasceu. Foi o comerciante, e não o antigo mestre de corporações, que se transformou em chefe da oficina moderna. Em quase todos os lugares houve uma luta encarniçada entre a manufatura e os ofícios”. (p. 447)

11 Du sens: essais sémiotiques. Paris, Seuil, 1970.

12 Não esqueçamos que os empregados e os membros subalternos da família não partilham, obrigatoriamente, esse kairos fantasmático. 
